\title{
ВMJ Global Health Private sector engagement and contributions to immunisation service delivery and coverage in Sudan
}

\author{
Nada Ahmed, ${ }^{1}$ Denise DeRoeck, ${ }^{2}$ Nahad Sadr-Azodi ${ }^{3}$
}

To cite: Ahmed N, DeRoeck D, Sadr-Azodi N. Private sector engagement and contributions to immunisation service delivery and coverage in Sudan. BMJ Glob Health 2019;4:e001414. doi:10.1136/ bmjgh-2019-001414

Handling editor Seye Abimbola

Received 13 January 2019 Revised 9 February 2019 Accepted 15 February 2019

\section{Check for updates}

\section{(c) Author(s) (or their} employer(s)) 2019. Re-use permitted under CC BY-NC. No commercial re-use. See rights and permissions. Published by BMJ

${ }^{1}$ Department of Maternal and Child Health, Republic of Sudan Federal Ministry of Health, Khartoum, Sudan

${ }^{2}$ Independent Consultant, Waltham, Massachusetts, USA ${ }^{3}$ Health \& Nutrition Section, UNICEF Regional Office for the Middle East and North Africa, Amman, Jordan

Correspondence to

Nahad Sadr-Azodi;

nsadrazodi@unicef.org

\section{ABSTRACT}

For more than two decades, the private sector in the Sudan (henceforth, Sudan), including non-governmental organisations and for-profit providers, has played a key role in delivering immunisation services, especially in the conflict-affected Darfur region and the most populated Khartoum state. The agreements that the providers enter into with state governments necessitate that they are licenced; follow the national immunisation policy and reporting and supervision requirements; use the vaccines supplied by government; and offer vaccinations free-ofcharge. These private providers are well integrated into the states' immunisation programmes as they take part in the Ministry of Health immunisation trainings and district review meetings and they are incorporated into annual district immunisation microplans. The purpose of this article is to describe the private sector contributions to equitable access to immunisation services and coverage, as well as key challenges, lessons learned and future considerations. Fifty-five per cent of private health facilities in Sudan (411 out of 752) provide immunisation services, with $75 \%$ (307 out of 411) based in Khartoum state and the Darfur region. In 2017, private providers administered around $16 \%$ of all third doses of pentavalent (diphtheria, pertussis, tetanus, hepatitis B and Haemophilus influenzae type b) vaccines to children. Private health providers of immunisation services have especially been critical in filling the gaps in government services in hard-to-reach or conflict-affected areas and among marginalised populations, and thus in reducing inequities in access. Through its experience in engaging the private sector, Sudan has learned the importance of regulating and licencing private facilities and incorporating them into the immunisation programme's decision-making, planning, regular evaluation and supervision system to ensure their compliance with immunisation guidelines and the overall quality of services. In moving forward, strategic engagement with the private sector will become more prominent as Sudan transitions out of donors' financial assistance with its projected income growth.

\section{INTRODUCTION}

As countries strive to reach the goals of the Global Vaccine Action Plan (GVAP) 20112020, more attention is being paid to the role that private, for-profit and nonprofit/
Summary box

- The global immunisation community is increasingly urging countries to engage more closely with the private sector in coordinating, planning and monitoring immunisation activities, particularly to reduce inequities in availability of services between geographic areas and population groups and increase overall coverage of immunisation services.

- Given the prolonged conflict, economic turmoil and limited human and institutional capacity of the government, Sudan has explored innovative ways of regulating, integrating and expanding partnerships with private providers to deliver health and immunisation services to inaccessible and difficult-to-reach populations.

- Overall, private/non-governmental health providers administered approximately $16 \%$ of the third dose of pentavalent vaccine given to children in 2017.

- In moving forward, ensuring effective public-private collaboration will become more critical to address service gaps and inequities especially as Sudan, with its projected income growth, is preparing to enter the accelerated Gavi transition phase, during which financial support will wind down.

non-governmental, health providers (henceforth, collectively referred to as 'private' providers) can play or are playing in the provision of immunisation services. These providers may offer services in areas where public facilities are lacking, thereby helping to reduce inequities in the availability of services between geographic areas and population groups, and increasing overall coverage of immunisation services.

In recognition of this role, the global immunisation community is increasingly urging countries to engage more closely with the private sector in coordinating, planning and monitoring immunisation activities. In April 2017, the WHO's Strategic Advisory Group of Experts (SAGE) recommended that national immunisation programmes increase their collaboration and communication with private providers, and as a first step, assess the 
private sector's role in immunisation service delivery. ${ }^{1}$ Moreover, in the 2017 SAGE Decade of Vaccines GVAP Assessment Report, one of the key recommendations stated that 'Countries should broaden and deepen their engagement with civil society organisations to enhance the performance and reach of their national immunisation programmes'.

The WHO also produced a guidance note to assist countries in improving their collaboration with private providers in the delivery of immunisation services. Such engagement not only contributes to increasing vaccination coverage and equity but also to improving the quality of immunisation services delivered by private providers and their reporting to the government of vaccinations administered, vaccine-preventable diseases (VPDs) and adverse events following immunisation (AEFI) - two areas where the private sector has been traditionally weak in many countries. ${ }^{34}$

Although there is a growing interest in this topic, only a limited number of reports and papers in the literature have, to date, examined the role of the private sector in immunisation in low- and middle-income countries ${ }^{45}$ or described in detail private sector involvement in immunisation, with the few recent examples from Asia and Africa. ${ }^{6-10}$ This paper reviews a relatively well-established and formalised collaboration between the government and the private sector in immunisation planning and service delivery in the Sudan (henceforth, Sudan). It also discusses the growth of private providers; their integration into the country's immunisation system; their contribution to immunisation service delivery; and challenges, lessons learnt and future considerations to ensure effective collaboration in light of discussions around transitioning out of donor financial assistance.

\section{CONTEXT AND IMMUNISATION PERFORMANCE}

Sudan became independent in 1956 and has since experienced intermittent civil war. Following the secession of South Sudan in 2011, the country faced several economic shocks from the loss of oil revenue and reduced income. At the same time, South Sudan's civil war has led to an influx of refugees into Sudan's borders. ${ }^{11}$ The country has been eligible to receive financial support for immunisation from Gavi, the Vaccine Alliance since 2002. However, given Sudan's recent economic growth, as per the World Bank's estimated gross national income, it is anticipated to enter an accelerated transition phase in 2020 with an expectation that it fully finances its immunisation programme by 2025 .

Despite the ongoing challenges, the latest WHOUnicef estimated coverage rate for the third dose of pentavalent (diphtheria, pertussis, tetanus, hepatitis B and Haemophilus influenzae type b) vaccine ('Penta3') in Sudan is $95 \%$. However, there is a significant drop in coverage between the first dose of measles-containing vaccine $(90 \%)$ and the second dose $(72 \%){ }^{12}$ The 2014
Multiple Indicator Cluster Survey also showed disparities in coverage by wealth quintile, geographical areas and mothers' education. ${ }^{13}$ Given the prolonged conflict, economic turmoil and limited human and institutional capacity of the government, Sudan in the past two decades has explored innovative ways to regulate, integrate and expand partnerships with private providers in delivering health and immunisation services to inaccessible and difficult-to-reach populations.

\section{Regulatory system and agreements between the government and private providers}

The role of the private sector in immunisation in Sudan was limited until the mid to late 1990s, when most providers did not report vaccinations to the government, and their services were largely unregulated. This dynamic started to change in 1995 when the state Ministry of Health $(\mathrm{MoH})$ in Khartoum began to recognise the sector's potential as a 'gap filler' to increase coverage of immunisation and other essential health services in areas underserved by the public sector. To realise this potential, the Khartoum state $\mathrm{MoH}$ established a regulatory framework for immunisation services by non-governmental providers and integrated these providers into the state's immunisation programme-a system that many other states in Sudan have since emulated.

All non-governmental organisation (NGOs) and for-profit providers in Khartoum must be registered by the state-level $\mathrm{MoH}$ before they can deliver specific services, such as curative care, immunisation and other maternal and child health interventions. Health facilities must also meet certain quality standards-determined by state inspections-to obtain and maintain their licence. NGOs active in states other than Khartoum are registered and regulated by the Humanitarian Aid Commission. In addition, those interested in providing vaccination services in any state are required to sign a memorandum of understanding (MoU) with the state $\mathrm{MoH}$.

Under these agreements, the government provides the private facilities with free bundled vaccines, along with data collection forms (to report vaccine doses administered, VPDs and AEFIs). Staff involved in immunisation also take part in regular trainings in vaccination and disease surveillance activities, as well as invited to attend monthly review meetings in their districts. In return, private providers are required to comply with the terms of the MoU, which includes administering all vaccines free-of-charge; following the national immunisation policy and the vaccination schedule; submitting monthly vaccination, disease and AEFI reports; and receiving regular supervisory visits to ensure that quality standards are met (eg, in vaccine and cold chain management, vaccine administration). Private providers are also expected to procure and maintain their own cold chain equipment, although in some cases, state immunisation programmes have 
provided NGOs with equipment deemed necessary to sustain services. To enforce these terms, providers must submit their monthly reports to the district immunisation officer before they can receive the next month's vaccine supply. If a provider has been found to be charging patients for immunisation, for which there is some anecdotal evidence, or is not meeting quality standards, their licence to provide vaccination is revoked, as has happened on occasion.

\section{Integrating private providers into the immunisation programme}

While many countries have arrangements in which private providers are given free vaccines from the government-usually in exchange for regular vaccination reports-Sudan is unique in the region in the extent to which non-public providers are integrated into the national immunisation programme in several states and treated in many respects the same as public providers. In these states, private health facilities are included in the microplans and the mapping of services that the immunisation programme undertakes each year as part of the states annual needs assessment of health services (figure 1). ${ }^{14}$

If gaps in coverage of vaccination services are found in a geographical area, the programme may ask a private provider to establish immunisation services within its existing facilities or to set up a new outreach site. The facilities are then responsible for providing immunisation services in their designated catchment area-under the supervision of the district immunisation officer-as well as other routine immunisation programme activities, such as default tracking and social mobilisation. While this process most often involves NGOs, a few for-profit facilities, such as private maternity hospitals in underserved areas, have also become part of this collaborative arrangement.

In addition to routine immunisation service delivery, national and international NGOs have also conducted immunisation campaigns (eg, polio and measles) in conflict-affected areas, in coordination with the district immunisation officer. Moreover, several private hospitals and paediatric clinics serve as sites for the country's

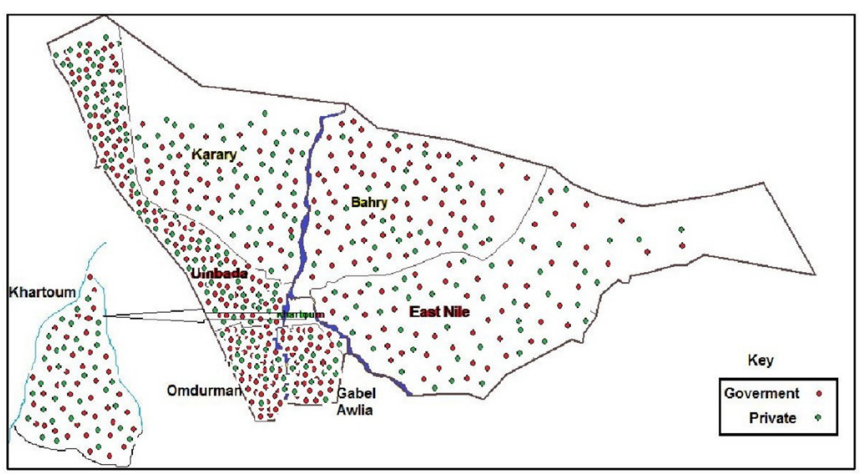

Figure 1 Map showing distribution of health facilities by public and private sectors in Khartoum state, 2017.
VPD surveillance system, such as polio, measles, rubella and meningitis.

The integration of the private sector in immunisation extends to the decision-making and advisory process. For-profit providers and NGOs are represented on both state-level technical immunisation committees and health coordinating task forces. Representatives of national and international NGOs serve on the country's Interagency Coordinating Committee/National Health Sector Coordinating Committee, which oversees immunisation activities at the national level, while the national immunisation technical advisory group includes representatives of paediatric and obstetrics and gynaecology associations.

Thus far, the private sector is incentivised by receiving free bundled vaccines and occasionally, NGOs may benefit from free cold chain equipment and/or the placement of government vaccinators in their facilities. It is believed that private health facilities have leveraged this partnership with the federal and state immunisation programmes to promote their health services and subsequently increase their client base. However, there have been no studies or evaluation to substantiate this assertion. The MoH has expressed interest in developing a national strategic framework and guidelines that specify the rules of engagement and expectations with the private sector throughout Sudan.

\section{Expansion of private providers in the delivery of primary health care and immunisation services}

In the past two decades, Sudan has seen a dramatic increase in the number of health facilities managed by the private sector, including those operated by national or international NGOs and for-profit providers. In Khartoum state, for instance, there were 30-40 NGO-operated health facilities in 1995. By 2002, as part of the state's primary healthcare expansion plan, more than 100 NGOs submitted proposals to the state primary healthcare directorate for licences. Currently, there are a total of 382 privately-run primary healthcare facilities in Khartoum-244 operated by NGOs (64\%) and 138 $(36 \%)$ by for-profit entities (table 1). Besides Khartoum state, NGOs play a key role in providing primary health services in especially conflict-affected states, such as in Darfur, where 49 NGOs provided immunisation services to more than 57000 children $(15.5 \%$ of total target population) in 2017.

There are nearly 6000 health facilities in Sudan, of which 752 are operated by the private sector. Of the 752 private health facilities, $411(55 \%)$ provided immunisation services and 307 of these $(75 \%)$ are based in Khartoum state and Darfur region (table 1). Sixty-five per cent (267) of the 411 facilities are operated by NGOs, whereas $35 \%$ (144) are for-profit facilities. The proportion of private health facilities offering immunisation services varies widely by state-from $\leq 10 \%$ (in four states) to $100 \%$ (in three states). In nine of the country's 18 states, 
Table 1 Participation of public and private health facilities in immunisation service delivery in Sudan by state and type of provider, 2017

\begin{tabular}{|c|c|c|c|c|c|c|c|c|}
\hline \multirow[b]{2}{*}{ State } & \multicolumn{2}{|l|}{ Public* } & \multicolumn{2}{|l|}{ NGOs } & \multicolumn{2}{|c|}{ Private for-profit } & \multirow{2}{*}{$\begin{array}{l}\text { Total no. } \\
\text { private } \\
\text { health } \\
\text { facilities } \\
\text { (NGOs and } \\
\text { for-profit) }\end{array}$} & \multirow[b]{2}{*}{$\begin{array}{l}\text { Total no. (\%) } \\
\text { private health } \\
\text { facilities } \\
\text { providing } \\
\text { immunisation }\end{array}$} \\
\hline & $\begin{array}{l}\text { No. health } \\
\text { facilities }\end{array}$ & $\begin{array}{l}\text { No. }(\%) \text { health } \\
\text { facilities } \\
\text { providing } \\
\text { immunisation }\end{array}$ & $\begin{array}{l}\text { No. } \\
\text { health } \\
\text { facilities }\end{array}$ & $\begin{array}{l}\text { No. }(\%) \text { health } \\
\text { facilities } \\
\text { providing } \\
\text { immunisation }\end{array}$ & $\begin{array}{l}\text { No. } \\
\text { health } \\
\text { facilities }\end{array}$ & $\begin{array}{l}\text { No. }(\%) \text { health } \\
\text { facilities } \\
\text { providing } \\
\text { immunisation }\end{array}$ & & \\
\hline Blue Nile & 155 & 75 (48\%) & 0 & $0(0.0 \%)$ & 20 & $20(100 \%)$ & 20 & $20(100 \%)$ \\
\hline Central Darfur & 94 & $44(47 \%)$ & 20 & $15(75 \%)$ & 3 & $0(0 \%)$ & 23 & $15(65 \%)$ \\
\hline East Darfur & 63 & $40(63 \%)$ & 7 & $7(100 \%)$ & 6 & $0(0 \%)$ & 13 & 7 (54\%) \\
\hline Gazira & 940 & $846(90 \%)$ & 3 & $0(0 \%)$ & 18 & $2(11 \%)$ & 21 & $2(9.5 \%)$ \\
\hline Gedaref & 309 & $282(91 \%)$ & 0 & $0(0 \%)$ & 0 & $0(0 \%)$ & 0 & $0(0 \%)$ \\
\hline Kassala & 292 & $142(49 \%)$ & 13 & $10(77 \%)$ & 24 & 19 (79\%) & 37 & 29 (78\%) \\
\hline Khartoum & 449 & $437(97 \%)$ & 244 & $203(83 \%)$ & 138 & $47(34 \%)$ & 382 & $250(65 \%)$ \\
\hline North Darfur & 268 & $220(82 \%)$ & 31 & $10(32 \%)$ & 5 & $0(0 \%)$ & 36 & $10(28 \%)$ \\
\hline North Kordofan & 419 & $305(73 \%)$ & 3 & $3(100 \%)$ & 25 & $10(40 \%)$ & 28 & $13(46 \%)$ \\
\hline Northern & 248 & $128(52 \%)$ & 0 & $0(0 \%)$ & 2 & $2(100 \%)$ & 2 & $2(100 \%)$ \\
\hline Red Sea & 139 & $83(60 \%)$ & 0 & $0(0 \%)$ & 19 & 17 (90\%) & 19 & $17(90 \%)$ \\
\hline River Nile & 369 & $325(88 \%)$ & 5 & $1(20 \%)$ & 7 & $4(57 \%)$ & 12 & $5(42 \%)$ \\
\hline Sennar & 395 & $352(89 \%)$ & 1 & $1(100 \%)$ & 8 & $5(63 \%)$ & 9 & $6(67 \%)$ \\
\hline South Darfur & 266 & $173(65 \%)$ & 31 & $11(36 \%)$ & 3 & $3(100 \%)$ & 34 & $14(41 \%)$ \\
\hline South Kardofan & 191 & 148 (77\%) & 2 & $0(0 \%)$ & 13 & $1(8 \%)$ & 15 & $1(7 \%)$ \\
\hline West Darfur & 78 & 75 (96\%) & 13 & $6(31 \%)$ & 16 & $5(31 \%)$ & 29 & $11(38 \%)$ \\
\hline West Kordofan & 216 & 167 (77\%) & 0 & $0(0 \%)$ & 2 & $2(100 \%)$ & 2 & $2(100 \%)$ \\
\hline West Nile & 336 & 203 (60\%) & 16 & $0(0 \%)$ & 54 & 7 (13\%) & 70 & 7 (10\%) \\
\hline Total & 5227 & 4045 (77\%) & 389 & $267(69 \%)$ & 363 & $144(40 \%)$ & 752 & $411(55 \%)$ \\
\hline
\end{tabular}

*Public facilities include those operated by government, military, police, National Health Insurance and National Security.

more than half of all private providers offer immunisation services.

Private providers are especially important stakeholders in the immunisation programme in Khartoum state, where $83 \%$ of NGO health facilities and $34 \%$ of for-profit facilities provide vaccination. The proportion of NGO facilities providing vaccination is similar to that of government facilities both in Khartoum state (NGOs $83 \%$ vs public $85 \%$ ) and in Sudan as a whole (NGOs $69 \%$ vs public $74 \%$ ) (figure 2).

Generally, for-profit facilities are less likely to offer immunisation services (40\% overall) compared with the NGOs (69\% overall). However, for-profit providers play a crucial role in several states (eg, Northern, Red Sea and West Kordofan) where there are no NGOs offering immunisation services. In these states, $90 \%-100 \%$ of for-profit facilities offer vaccination (table 1 ).

Overall, the private health providers administered approximately $16 \%$ of Penta3 vaccines given to children in 2017 (table 2), which is generally higher than private sector estimates from low- and middle-income countries. ${ }^{5}$ (Private providers submit regular reports to the district managers and the state $\mathrm{MoH}$ consolidates the data from the districts and forwards them to the federal level monthly. The lead author of this paper, who supervised the federal immunisation programme until mid-2018, worked closely with the state immunisation coordinators to review and disaggregate the existing data for 2017. The federal immunisation team also facilitated a series of data verification and validation and qualitative

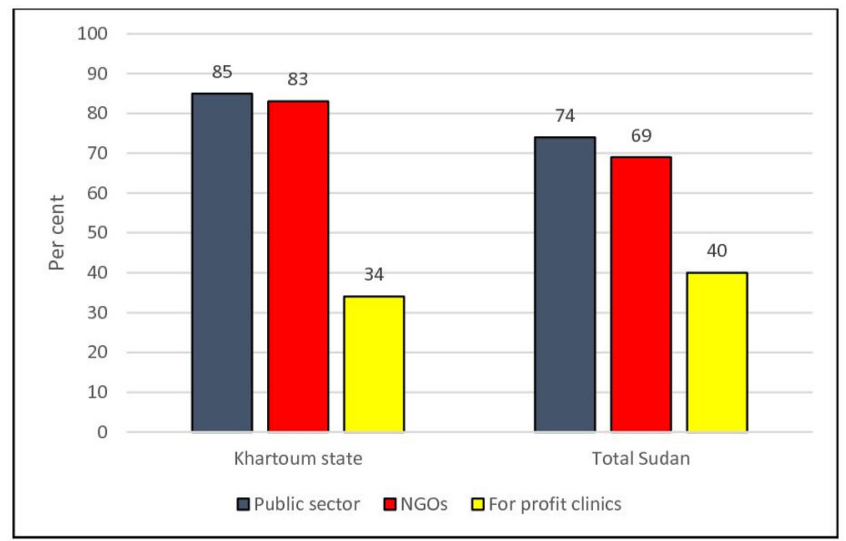

Figure 2 Per cent of health facilities that provide immunisation services by sector in Sudan and in Khartoum state, 2017. 
Table 2 Number and per cent of doses of pentavalent vaccine provided to children through the private (NGO and for-profit) sector, by state, 2017

\begin{tabular}{|c|c|c|c|c|}
\hline State & $\begin{array}{l}\text { Total target } \\
\text { population }\end{array}$ & $\begin{array}{l}\text { No. }(\%) \text { of infants } \\
\text { who received third } \\
\text { pentavalent dose }\end{array}$ & $\begin{array}{l}\text { No. of third } \\
\text { pentavalent doses } \\
\text { provided through } \\
\text { private sector }\end{array}$ & $\begin{array}{l}\% \text { of third } \\
\text { pentavalent dose } \\
\text { provided through } \\
\text { private sector }\end{array}$ \\
\hline Blue Nile & 43167 & 36724 (85.1\%) & 6174 & 16.8 \\
\hline Central Darfur & 43334 & 45334 (104.6\%) & 19494 & 43.0 \\
\hline East Darfur & 47267 & 45208 (95.6\%) & 8376 & 18.5 \\
\hline Gazira & 196589 & 194358 (98.9\%) & 835 & 0.4 \\
\hline Gedaref & 96810 & 91964 (95\%) & 617 & 0.7 \\
\hline Kassala & 80652 & 76486 (94.8\%) & 19391 & 25.4 \\
\hline Khartoum & 243932 & 235192 (96.4\%) & 112037 & 47.6 \\
\hline North Darfur & 107397 & 106353 (99\%) & 12902 & 12.1 \\
\hline North Kordofan & 81445 & 81502 (100.1\%) & 3533 & 4.3 \\
\hline Northern & 20693 & 20412 (98.6\%) & 421 & 2.1 \\
\hline Red Sea & 26695 & 24167 (90.5\%) & 4877 & 20.2 \\
\hline River Nile & 45248 & 44659 (98.7\%) & 1342 & 3.0 \\
\hline Sennar & 73578 & 73504 (99.9\%) & 1692 & 2.3 \\
\hline South Darfur & 150161 & 122282 (81.4\%) & 1223 & 1.0 \\
\hline South Kordofan & 61307 & $50583(82.5 \%)$ & 506 & 1.0 \\
\hline West Darfur & 52443 & $50091(95.5 \%)$ & 15376 & 30.7 \\
\hline West Kordofan & 64235 & 62001 (96.5\%) & 5436 & 8.8 \\
\hline White Nile & 85207 & 78193 (91.8\%) & 11587 & 14.8 \\
\hline Total & 1520161 & $1439013(94.7 \%)$ & 225818 & 15.7 \\
\hline
\end{tabular}

discussions and phone calls with the states' focal points.) The private providers' contribution ranged from $1 \%$ or less (in four states), most of which have a small NGO or private sector presence, to $48 \%$ in Khartoum state. Their contribution to Penta3 coverage was $>20 \%$ in five states, including three (Red Sea, Kassala and West Darfur) where $45 \%-100 \%$ of private providers of immunisation services are based in for-profit facilities. In the conflict-affected states of Central and West Darfur, the private sector reached $43 \%$ and $31 \%$ of the children, respectively. In addition, private providers reported $10 \%$ of all Acute Flaccid Paralysis cases notified nation-wide in 2017.

One example of a key NGO provider in Khartoum is Ana Sudan, a national NGO largely funded by charitable donations and membership fees. The organisation began providing health services through three health facilities in the state in 1997 and gradually expanded to 33 health facilities in seven localities-all of which offer immunisation services. This NGO contributed $5.2 \%$ of all Penta3 vaccinations given in Khartoum state in 2017.

Another example is the Italian Emergency Health Centre established by the Italian Embassy in 2005 to provide fixed health services to refugees from South Sudan displaced by the civil war and living in hard-to-reach and insecure areas. By constructing a fixed facility, building networks over time with people in the area and mobilising the community, immunisation coverage climbed from 50\%-60\%-when all vaccinations were provided through campaigns-to nearly universal coverage by 2017.

\section{Challenges and lessons learned in engaging with private providers and future considerations}

Private providers have made an important contribution to Sudan's immunisation programme and its efforts to improve vaccination coverage-from $62 \%$ for diphtheria-tetanus-pertussis third dose in 2000 to $95 \%$ for Penta3 in 2017 (using WHO-Unicef estimates). Moreover, as in Malawi, private facilities in Sudan participate in 'cost sharing' by providing the venues, health personnel, some of the cold chain and running costs. ${ }^{9}$ Without the private sector, the government would need to significantly increase its capital investment in health facilities and recurring personnel cost to fill gaps in services, especially in states like Khartoum.

Yet, this engagement has faced a number of challenges. For example, despite the government oversight described above, there are anecdotes of suboptimal quality standards and of the private sector charging 'fees' to beneficiaries for vaccination. Therefore, a key lesson learnt is the importance of the licencing process for private facilities and incorporating them into the immunisation programme's regular supervision and quality assurance system to ensure compliance with immunisation guidelines and policy. In addition, 
the experience in Sudan demonstrates the importance of making private providers feel that they are part of or have ownership in the delivery system and are accountable to it by taking part in regular planning, training, review and decision-making activities.

In moving forward, the Federal $\mathrm{MoH}$ is committed to further improving and leveraging its engagement with private providers in immunisation, especially in states, such as South Darfur and South Kordofan, where their participation is currently minimal or non-existent. Moreover, the government is intent on developing national guidelines and a strategy for expanding public-private collaboration in immunisation service delivery, which may include non-monetary incentives (eg, awards, public recognition, etc) and in-kind/monetary support (eg, covering operational costs, salaries, transport, cold chain equipment through the national health insurance programme-as is occurring in a pilot project in one state). In this regard, per request of the $\mathrm{MoH}$, Unicef is currently undertaking a private sector engagement study to better understand successful examples of public-private collaboration, practices and challenges related to vaccine procurement and reporting.

Future initiatives and studies should consider the demand aspects (eg, experiences and perceptions of the beneficiaries towards private facilities and quality of care), the quality of data reporting, and missed opportunities for vaccination. Additionally, government and partners should review the dynamics between state-level regulators/ authorities and private providers and include a comparative analysis of the states and their determinants for effective engagement with the private sector. It is also important to understand the role of external assistance-particularly to NGOs-and how a potential reduction or disruption in funding may impact service delivery in conflict-affected and low-resource areas.

\section{CONCLUSION}

Overall, private providers have been critical in filling gaps in government services in hard-to-reach areas and among marginalised populations, thus reducing inequities to access. Sudan's public health sector, especially at the state level, is collaborating closely with the private providers by supplying vaccines, injection devices and in some cases, cold chain equipment free-of-charge and vaccinators. Sudan's public-private sector engagement also represents an efficient approach and possible cost savings to the government. Future research and efforts in this area will inform the development of an overall strategic framework and national guidelines, especially at a critical time when Sudan is exploring a sustainable transition out of donor financial assistance and is seeking efficient means of covering the population, including the disadvantaged, with cost-effective health interventions, including immunisation.

Acknowledgements The paper was partially conceptualised during a regional workshop held in Jordan in September 2017 with wide participation of colleagues from Unicef headquarters, and regional and country offices; government counterparts; Gavi; Centers for Disease Control and Prevention (CDC), WHO, Global Health Development (GHD) and John Snow, Inc. The authors are grateful to Ekhlas Ibrahim, Mawahib Rashid, Ismael Aladani, Khalda Abdelgany, Nosiba Minni, Sudan Federal MoH; all coordinators and contributors from the 18 states; the support, encouragement and review of the Unicef Country Office senior management team, and Shaza Ahmed, Health and Nutrition Section; Daniel Ngemera and Celina Hanson, Unicef Regional Office for the Middle East and North Africa; Shalini Desai, WHO; Steve Cochi, CDC; Ezzeddine Mohsni, GHD; Ann Levin, Levin \& Morgan, LLC; and Kamel Senouci, Bill and Melinda Gates Foundation.

Contributors All three authors, NA, DD and NS-A contributed equally to the conceptualisation, preparations and finalisation of this paper.

Funding This work was partly funded by Gavi.

Disclaimer The authors alone are responsible for the views expressed in this publication and they do not necessarily represent the decisions, policy or views of the Sudan government and Unicef.

Competing interests None declared.

Patient consent for publication Not required.

Provenance and peer review Not commissioned; externally peer reviewed. Data sharing statement № additional data are available.

Open access This is an open access article distributed in accordance with the Creative Commons Attribution Non Commercial (CC BY-NC 4.0) license, which permits others to distribute, remix, adapt, build upon this work non-commercially, and license their derivative works on different terms, provided the original work is properly cited, appropriate credit is given, any changes made indicated, and the use is non-commercial. See: http://creativecommons.org/licenses/by-nc/4.0/.

\section{REFERENCES}

1. World Health Organization. Meeting of the strategic Advisory group of experts on immunization, April 2017 - conclusions and recommendations. Weekly epidemiological record. 2017: 92, 301-20.

2. World Health Organization. Assessment report of the global vaccine action plan strategic Advisory group of experts on immunization. Geneva, 2017. Report No: Licence: CC BY-NC-SA 3.0 IGO.

3. World Health Organization. Engagement of private/nongovernmental health providers in immunization service delivery: considerations for national immunization programmes. Geneva, 2017. Report No: License: CC BY SA-4.

4. Mitrovich $\mathrm{R}$, Marti M, Watkins $\mathrm{M}$, et al. A review of the private sector's contribution to immunization service delivery in low, middle and high-income countries. Background document presented to SAGE, 2017.

5. Levin A, Kaddar M. Role of the private sector in the provision of immunization services in low- and middle-income countries. Health Policy Plan 2011;26(Supple 1):i4-12.

6. Hagan JE, Gaonkar N, Doshi V, et al. Knowledge, attitudes, and practices of private sector immunization service providers in Gujarat, India. Vaccine 2018;36:36-42.

7. Patel MK, Capeding RZ, Ducusin JU, et al. Findings from a hepatitis $B$ birth dose assessment in health facilities in the Philippines: opportunities to engage the private sector. Vaccine 2014;32:5140-4.

8. Amarasinghe A, Davison L, Diorditsa S. Report of the survey on private providers' engagement in immunization in the Western Pacific region. Vaccine 2018;6.

9. Levin A, Munthali S. Role of Private Sector Providers in Malawi's National Immunization Program. Rockville, MD: Abt Associates Inc, 2018.

10. Levin A, Vodungbo V. Role of Private Sector Providers in Benin's National Immunization Program. Rockville, MD: Abt Associates Inc, 2018.

11. UNICEF. Immunization financing in Mena middle-income countries. Health and Nutrition, 2018.

12. WHO-UNICEF. Who vaccine-preventable diseases: monitoring system. 2018 global summary, 2018. Available: http://apps. who.int/immunization_monitoring/globalsummary/countries? countrycriteria\%5Bcountry\%5D\%5B\%5D=SDN [Accessed Oct 2018].

13. Central Bureau of Statistics, UNICEF Sudan. Multiple indicator cluster Survey 2014 of Sudan, final report. Khartoum, 2016.

14. Sadr-Azodi N, DeRoeck D, Senouci K. Breaking the inertia in coverage: mainstreaming under-utilized immunization strategies in the Middle East and North Africa region. Vaccine 2018;36:4425-32. 